\title{
MIRAR EL CERRO RICO. FORMAS \\ DE VER EN LA VILLA IMPERIAL DE POTOSÍ, SIGLOS XVI-XVIII ${ }^{1}$
}

Alejandra Vega Palma(a)

LOOKING AT THE CERRO RICO. WAYS OF SEEING IN THE

IMPERIAL VILLA OF POTOSÍ, XVI-XVIII CENTURIES

OLHAR O CERRO RICO. FORMAS DE VER NA VILLA

IMPERIAL DE POTOSÍ, SÉCULOS XVI-XVIII

Fecha de recepción: 11 de diciembre del 2020

Fecha de aprobación: 21 de diciembre del 2020

Disponible en línea: $1 .^{\circ}$ de enero del 2021

Sugerencia de citación:

Vega Palma, A. (2021). Mirar el Cerro Rico. Formas de ver en la Villa Imperial de Potosí, siglos xvi-XviII. Razón Crítica, 10, 147-170. https://doi.org/10.21789/25007807.1719

(1) El presente artículo forma parte de los resultados del proyecto Fondecyt 1120275 del cual la autora es la investigadora responsable. Un primer acercamiento al problema planteado fue una ponencia en el V Simposio Iberoamericano de Historia de la Cartografía, realizado en Bogotá, Colombia, en el 2014, y de la publicación de un resumen extendido de dicha comunicación oral en las actas del Congreso (Vega Palma, 2015).

(a) Alejandra Vega Palma

Doctora en Historia de la Universidad Católica de Chile

Profesora asociada de la Universidad de Chile, Chile

https://orcid.org/0000-0002-5284-4649

alvega@uchile.cl 


\section{R E S U M E N}

Este artículo discute las condiciones de producción de la iconografía potosina colonial y, en particular, aquella elaborada por artífices que conocieron de primera mano la Villa Rica, ya fuera como pasantes o como vecinos de la ciudad. En el cruce entre el campo de la cultura visual y de la reflexión sobre géneros y tipologías textuales, se propone una revisión de imágenes surgidas del siglo Xvi al xviII, las cuales muestran la fijación de una determinada forma de ver. Contra la insistencia habitual en hablar de formas convencionales de representación de Potosí y su Cerro Rico, se muestra que hay en la base de la repetición de estas imágenes un encuentro reiterado con una experiencia compartida del espacio circundante. El resultado, expresado en un doble perfil cónico del Cerro Rico y el Huayna Potosí (o pequeño Potosí) y la presencia de un pequeño cerro cónico que queda situado a la derecha del campo visual del observador, da cuenta de ejercicios de comunicación de una experiencia compartida y familiar

PALABRAS CLAVE: Representación; cultura visual; periodo colonial; vistas urbanas. 


\section{A B S T R A C T}

This article discusses the production conditions of colonial Potosí iconography, particularly that elaborated by architects who knew the Villa Rica first-hand, either as travelers or as residents of the city. At the crossing between the field of visual culture and the reflection on genres and textual typologies, a review of images that emerged from the XVI to the XVIII centuries is proposed. Such images depict the fixation of a certain way of seeing. Against the common determination of addressing conventional forms of representation of Potosí and its Cerro Rico, a reiterated encounter with a shared experience of the surrounding space is shown as the reason for the repetition of these images. The result, represented in a double conical profile of Cerro Rico and Huayna Potosí (or little Potosí), and the presence of a small conical hill located to the right of the observer's vision range, accounts for communication exercises of a shared and familiar experience.

KEYWORDS: representation; visual culture; colonial period; urban views.

\section{R E S U M O}

Este artigo discute as condições de produção da iconografia potosina colonial e, em particular, a elaborada por artífices que conheceram de primeira mão a Villa Rica, fosse como passantes, fosse como moradores da cidade. O cruzamento entre o campo da cultura visual e da reflexão sobre gêneros e tipologias textuais, é proposta uma revisão de imagens que surgiram do século XVI ao XVIII, as quais mostram a fixação de uma determinada forma de ver. Contra a insistência habitual de falar de formas convencionais de representação de Potosí e seu Cerro Rico, mostra-se que há, na base da repetição dessas imagens, um encontro reiterado com uma experiência partilhada do espaço circundante. O resultado, expresso no perfil duplo cônico da montanha Cerro Rico e do Huayna Potosí (ou pequeno Potosí) e na presença de uma pequena montanha cônica localizada à direita do campo visual do observador, demonstra exercícios de comunicação de uma experiência partilhada e familiar.

PALAVRAS-CHAVE: representação; cultura visual; período colonial; vistas urbanas. 


\section{N T R O D U C C I Ó N}

Este artículo explora una de las iconografías del éxito más conocidas del mundo hispanoamericano: aquella que representa la Villa Imperial de Potosí y su Cerro Rico. Sobre esta materia contamos con tres aportaciones relevantes: la obra de Richard Kagan (2000) y, muy recientemente, con los escritos de Rossana Barragán (2019) y Andrea Doré (2020). En estos trabajos aparece de manera muy elocuente la dimensión de éxito, expresada tanto en la temprana consolidación de una iconografía para representar la ciudad y su riqueza minera, como la notable difusión de estas imágenes en distintos escenarios.

Entre los rasgos que componen esta imagen común, se ha destacado la presencia de los emblemas del dominio hispano en América, que afirman visualmente la inscripción de la ciudad en el espacio imperial. Al mismo tiempo, se plantea que estas imágenes representan lo que la propia ciudad aportaba al imperio, destacando el Cerro Rico y las labores mineras como una cuestión clave de la imagen visual del asentamiento urbano. De este modo, no es tanto la ciudad sino su cerro el cual esconde riquezas mineras sin igual lo que particulariza la identidad de Potosí. Se trata de una iconografía que habría permitido encarnar el discurso colonial universalista de las glorias del imperio y del cristianismo desde uno de sus territorios y, como tal, sirvió a los fines ideológicos de la monarquía católica. Al mismo tiempo, desde la sociedad local colonizadora, esta imagen enunció el lugar específico de Potosí a la luz de los valores que dicho programa universal proclamaba: una lealtad a la Corona y un 
sustento material de sus intereses ${ }^{1}$. Lo interesante, desde mi punto de vista, es que esta enunciación adoptara un formato regular y específico. Es en torno a esta idea que se desarrollan las siguientes líneas.

En las obras referidas, Barragán (2019) y Doré (2020) exploran las condiciones de circulación globalizada de estas imágenes en diferentes soportes y contextos, mientras Kagan enfatiza en las tipologías diversas que caben bajo la denominación de vistas urbanas con las que se representa Potosí. Kagan (2000) distingue entre las imágenes producidas en Europa y para consumo europeo, y aquellas creadas en el entorno posotino, pensadas para dialogar con la sociedad local. Sugiere que las primeras se acercan a los typus, un término cartográfico para aludir a "[...] vistas urbanas que contienen algunos elementos reconocibles relacionados directamente con la ciudad representada pero luego aplicados en un contexto urbano genérico" (2000, p. 7). Las segundas representan sobre todo a la ciudad como civitas, es decir, como comunidad política. Con independencia del grado de convencionalidad con la que se recoja el entorno urbano, para Kagan lo relevante es la decisión de resaltar una historia, unas historias, que fundan el espacio colectivo y que le dan sentido.

En este artículo me interesa, como a Kagan, la cuestión de los diversos tipos de imágenes con las que se representa la ciudad y sus funciones específicas, es decir, la pregunta acerca de cómo se apropian y despliegan ciertas formas instituidas de representar en contextos particulares. La reflexión de Kagan sobre las tipologías de vistas urbanas puede relacionarse con una reflexión más amplia acerca de los géneros discursivos y las tipologías textuales. Los géneros son, siguiendo la propuesta clásica de Bajtin (1998), no solo el contenido temático, el estilo y la composición que caracterizan un enunciado, sino la relación de la totalidad de este con una esfera dada de comunicación (pp. 248 ss.). Referido al problema que nos ocupa, pensar en géneros nos permite reflexionar no solo respecto de las características formales y de contenido de una imagen, sino que también acerca de su existencia en el espacio social en relación con ciertas prácticas. Estas ideas pueden complementarse con la propuesta de comprensión de los tipos discursivos que presenta Mignolo (1982). Para este autor, las características formales de un texto nos permiten reconocer su adscripción a un género y, en esa

1 Todas estas ideas están ampliamente desarrolladas en las obras de Kagan, Barragán y Doré ya citadas. 
medida, permiten relevar una intención comunicativa. Sin embargo, esta puede ser diferente a aquella con la que una obra se comprende. Para efectos de nuestra discusión, se trata de una precisión relevante, pensando en la circulación de significados que no siempre acompañan de manera estable la circulación de las imágenes.

Tal como adelantó Kagan en su trabajo, las imágenes con las que se representó a Potosí durante el periodo colonial son vistas urbanas en un sentido muy amplio, coloquial, pero remiten en realidad a diferentes taxonomías con características formales diversas, siendo la "vista urbana" panorámica, con perspectiva a vuelo de pájaro solo una de ellas (2000, pp. 2-3). Se trata de una cuestión que, desde mi perspectiva, resulta fundamental, pues significa reconocer que en la producción de vistas urbanas intervienen actores heterogéneos, desplegando diferentes técnicas y soportes, diversas estrategias representacionales, con distintos fines y pensando en diferentes destinatarios o interlocutores.

Por eso es fundamental pensar en la localización de los objetos estudiados. En este artículo, nos centramos en una parte del corpus de imágenes de la Villa Imperial de Potosí, referidos específicamente a aquellos producidos desde el espacio representado o, en su defecto, con un conocimiento de primera mano de este entorno. Hecha esta aclaración, el corpus de imágenes resultante es muy variado, y lo componen dibujos, acuarelas, grabados, pintura de caballete y sobrerrelieves. Estos recubren, a la vez, diferentes géneros, tales como emblemas, vistas urbanas, plantas urbanas, paisajes urbanos, pinturas devocionales y conmemorativas. Hay saberes, formas de hacer, materiales, incluso espacios de producción diferentes, además de trayectorias biográficas previstas para los diferentes objetos $^{2}$. Existen diferentes marcos institucionales, además de personas y grupos, que producen y utilizan unos objetos que, aunque diversos, comparten convenciones, hábitos y modelos, repertorios de ideas, imágenes y asociaciones, prácticas sociales vinculadas con el ver, el dar a ver, el representar.

2 Me baso aquí en la formulación de Kopytoff (1991) acerca de la vida de los objetos. La aproximación desde diferentes tipos de objetos como una forma de acercarse a la cultura visual de un periodo tiene ya una amplia trayectoria. Véanse, entre otros, las obras Baxandall (1972), Alpers (1983) y Mitchell (1986), que abrieron el campo de la cultura visual. Buisseret (2003) da cuenta de prácticas convergentes entre la fabricación de mapas y pinturas, cuestión que está ampliamente tematizada en la obra de Besse (2000, 2009). Para el caso americano, destaco los trabajos realizados por Penhos (2005) y Silvestri (2012) respecto de la representación del territorio en un tiempo extenso que abarca la presente propuesta. 
Volver sobre la pregunta de los géneros y los tipos discursivos —o de imágenes, en este caso- parece una cuestión clave a la hora de valorar un corpus de imágenes que caracterizamos por su gran heterogeneidad. En particular, me parece una invitación a evitar aplicar criterios extemporáneos a estas imágenes, específicamente unos que pudieran insistir en su falta de concordancia con lo real. En efecto, la fijación de unas prácticas y unos nuevos formatos para dar cuenta del espacio urbano en el siglo xix (fueran estos los de la cartografía, los de los panoramas o, posteriormente, los de la fotografía aérea) supuso relegar al ámbito de la imprecisión — a veces enunciado, a veces implícito- a las imágenes construidas con otros criterios.

\section{Experiencia urbana y formas de ver}

Como adelantábamos, presentamos un recorte de la iconografía de Potosí que, reconociendo ámbitos de producción específicos, acoge de la misma manera la posibilidad de leer convenciones, hábitos y modelos, repertorios de ideas, imágenes y asociaciones compartidas sobre la base de prácticas sociales vinculadas con el ver, el dar a ver, el representar. Me centraré en aquellas imágenes cuyos artífices poseen una experiencia común: la de haber usado la ciudad, ya sea como vecinos o pasantes. Los miembros de la élite social y económica de la ciudad, funcionarios del aparato burocrático colonial local o de otros niveles de la administración colonial, depositarios de diversas tradiciones de producción de imágenes, trabajan a partir de un conocimiento del espacio retratado.

Esta experiencia compartida me parece fundamental. Permite sustentar la hipótesis de que la repetición de formas convencionales con la que se ha leído en general la producción de la exitosa iconografía de Potosí se alimenta, en el ámbito local, de la institución de ciertas "formas de ver" el entorno natural y urbano ${ }^{3}$.

La expresión "formas de ver" para pensar la producción de imágenes se la debemos a John Berger (2010), quien propuso reconocer la experiencia sensible como una dimensión de nuestro ser social. Para este autor, "la vista llega antes que las palabras. El niño mira y ve antes de hablar" (2010, p. 7, traducción propia). Sin embargo, la vista "no es una pura reacción mecánica a ciertos estímulos" puesto que "solo vemos lo que

3 Una primera formulación de estas ideas se encuentra en Vega (2019), referidas a la obra de Bartolomé Arzáns de Orsúa y Vela, donde se trabaja en particular la cuestión del relato corográfico. 
miramos", es decir, solo vemos en relación con nuestra experiencia y las formas que adopta en nosotros la experiencia colectiva de la vista (Berger, 2010, pp. 8-9). Se trata de un planteamiento que ha sido ampliamente revisitado por estudios en el campo de la cultura visual. Así, por ejemplo, Mieke Bal nos recuerda que el concepto de ver se preocupa por los efectos de la mirada de una figura (sea esta narrada o pintada) sobre la imaginación del lector o el ver del espectador, de forma que el modo de ver es a la vez una posición fijada y que fija (2002, pp. 35-36). Miramos como sujetos situados, a partir de experiencias instituidas e institucionalizadas, y el resultado de nuestra mirada, plasmado en representaciones visuales, realimenta nuestras formas de ver.

A partir de estos planteamientos preliminares, nos acercamos a la iconografía de Potosí. Recordemos, como contexto indispensable, que Potosí fue un yacimiento minero fundamental para el imperio hispano desde el momento en que se incorporó a las dinámicas coloniales; se transformó, en pocas décadas, en la principal mina de plata. Como tal, devino en un centro neurálgico de la economía de la América meridional, al integrar territorios distantes mediante el desplazamiento de una importante mano de obra indígena y otros actores sociales, que convergieron en torno a actividades metalúrgicas, artesanales y comerciales. También generó una demanda de una vasta gama de productos destinados al consumo de la ciudad (Assadourian, 1983; Medinaceli, 2011).

Luego de un crecimiento explosivo en la segunda mitad del siglo Xvi, Potosí pasó a ser uno de los asentamientos urbanos más grandes de su tiempo, con una población estimada de 160.000 habitantes hacia 1610, siendo cerca de la mitad de ellos indígenas. Esta proporción se mantuvo a lo largo del siglo XviI (Cook, 2010, pp. 300-316). Aunque por los mismos años el rendimiento de la mina comenzó a decaer, Potosí permaneció como un nodo articulador de la economía y la sociedad regional de los Andes centro-sur hasta bien entrado el siglo XviII (Tandeter, 2002, p. 13).

La base territorial de esta concentración fue el proceso de reorganización urbana impulsado por el virrey Francisco de Toledo en Potosí con el ensanche y rectificación de calles, el trazado de la plaza, la organización de barrios y la construcción del río artificial denominado "La Ribera”, que debía alimentar los molinos destinados procesar el material mineral (Medinaceli, 2011, p. 44).

La primera imagen que se conserva de este espacio es el grabado titulado "Cerro de Potosi", incluido en la Primera parte dela Chronica del Perú 


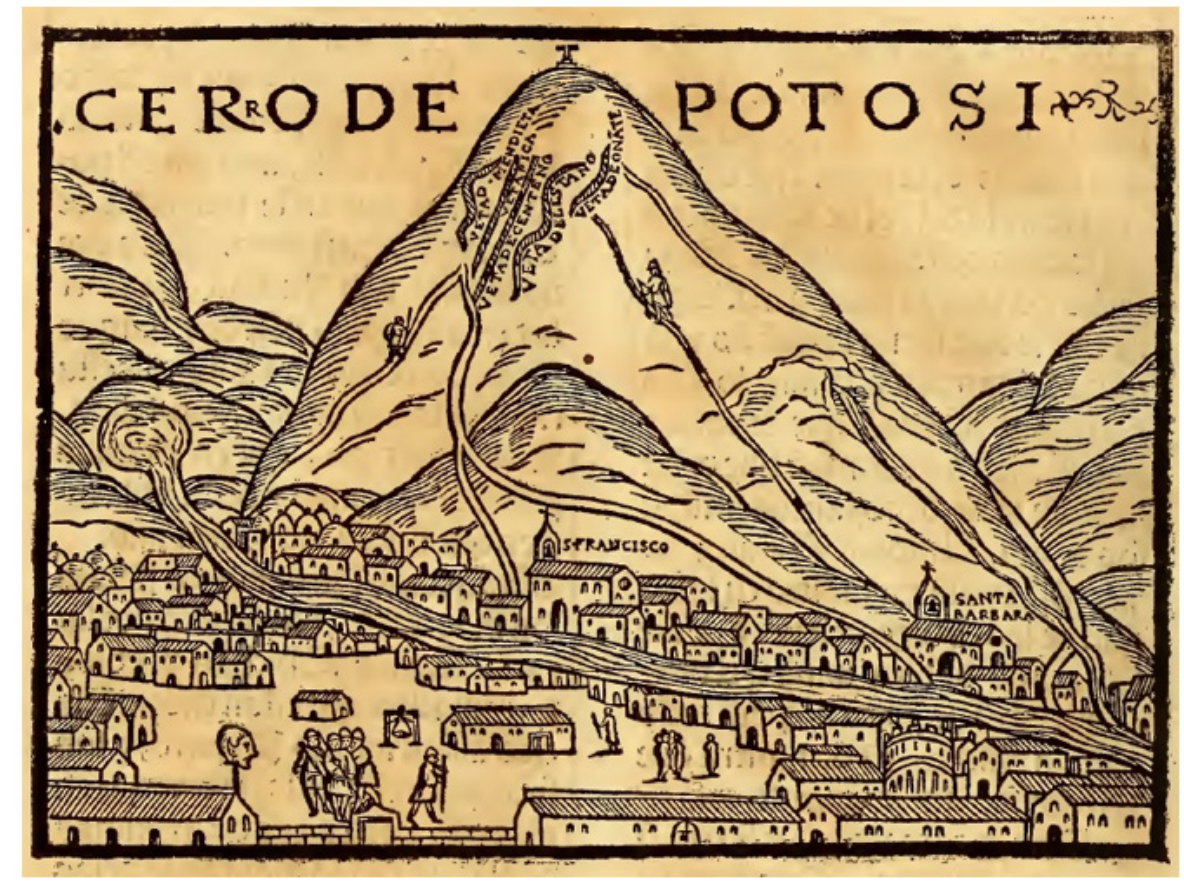

Nota. Publicado en la Primera parte dela Chronica del Perú (folio CXIIv) por Pedro Cieza de León, 1553, John Carter Brown Library.

de Pedro Cieza de León, impresa en Sevilla en 1553 (figura 1). Se sabe que Cieza estuvo en Perú entre 1548 y 1550, donde inició la redacción de su monumental obra. Durante su vida, solo alcanzó a ver la luz la primera parte de este escrito, consagrado a la descripción geográfica del Perú (Pease, 1995, p. 25). Martín de Montesdoca ofició como impresor de la obra, cuya publicación fue supervisada por el propio Cieza en Sevilla. El grabado en madera que comentamos es uno de los numerosos grabados que integran el volumen, todos de autor desconocido (Wagner, 1982, pp. 32-33). De todos ellos, es el único que muestra rasgos figurativos que aluden al espacio representado. ${ }^{4}$

4 La obra incluye 12 tipologías de viñetas distintas, entre las que destacan una imagen que representa el lago Titicaca (Cieza de León, 1553, CXVIIv) y otra que presenta la ciudad del Cuzco (1553, CVIIv). Ambas carecen de elementos figurativos que remitan a estos espacios efectivos, los que quedan evocados únicamente por la inscripción de los respectivos topónimos a modo de leyenda en la imagen. Con la excepción de una lámina con auquénidos (CXXIVv), todas las otras láminas empleadas son imágenes convencionales, la mayor parte de las cuales se repiten en diferentes secciones del libro, 8 y hasta 13 veces a lo largo del volumen. 
Partamos por la descripción que hace de Kagan esta pequeña imagen:

"[...] la ciudad se representa de modo fundamentalmente convencional

- un conjunto de edificaciones de estilo europeo en las laderas de

un río, aunque al modo de las vistas urbanas definidas como typus-

[...] Contenía elementos que derivaban de información de primera

mano [...]. El énfasis que Cieza de León otorga al Cerro Rico en su

descripción narrativa de Potosí se repite en el grabado en madera, en el cual la altura del cerro se exagera de manera intencionada para llamar la atención acerca de su gran riqueza minera (2000, p. 102).

En esta interpretación, los elementos que derivan de una información de primera mano quedan subsumidos en la función retórica atribuida al grabado. Por mi parte, quiero insistir en que esa dimensión retórica evidente - que involucra una política de la representación relacionada con la cuestión del éxito del imperio y de la Villa Rica- tiene como referente una experiencia y una cultura visual situada.

El grabado que representa a Potosí se encuentra en el capítulo que Cieza de León le dedica al descubrimiento de la mina. Como contexto general, el relato vehicula dos ideas recurrentes en los escritos del periodo: la riqueza superlativa del yacimiento y la mano de obra indígena que trabaja extrayendo el mineral (1995, pp. 287-292) ${ }^{5}$. Entrelazados con estos temas reiterados, la descripción aporta huellas sutiles de la experiencia sensible de su autor. Se trata de pasajes que pueden pensarse en relación con la función narrativa de la focalización, la cual, siguiendo a Mieke Bal, son aquellos en que se guía la mirada por medio de operaciones lingüísticas precisas (2002, p. 38).

Como leemos a continuación, Cieza nos orienta hacia el dibujo mismo del cerro, devenido grabado en la edición de 1553, cuyo título además es justamente "Cerro de Potosí". Al referir su "descubrimiento”, informa que un tal Villarroel “[...] dio en esta grandeza que está en vn collado alto de la

5 En la plataforma virtual Proyecto glosas croniquenses, desarrollada por Lydia Fossa, puede constatarse que los temas de la riqueza y la mano de obra indígena estructuran el universo de lo escrito acerca de Potosí en el periodo (s. f.). Como tal, están presentes en otros autores quienes, como Cieza, conocieron Potosí de primera mano: el oidor de Audiencia de Charcas, Juan de Matienzo, autor de Gobierno del Perú (1567/1967); el licenciado Polo de Ondegardo, quien escribiera en 1571 su Notables daños de no guardar a los yndios sus fueros, y el obispo de Charcas, Hernando de Santillán, autor de Relación del origen, descendencia, política y gobierno de los Incas (ca. 1563). En estos textos, Potosí aparece como parte de una unidad que es geográfica e histórica, al hablarse de Porco y Potosí (Fossa, s. f.). 
postura que aquí va figurado: el más hermoso y bien asentado que ay en aquella comarca" (Cieza de León, 1996, p. 290, énfasis propio). ${ }^{6}$ Luego, al dar cuenta del procedimiento empleado para separar la plata extraída de la mina, evoca lo visto, y declara que "[...] los indios se yvan con el metal a los altos de la redonda dél a sacar plata. Llaman a estas formas Guayras. Y de noche ay tantas dellas por todos los campos y collados que parescen luminarias" (1996, p. 291, énfasis propio).

Nada de esto aparece, sin embargo, en el grabado que comentamos, lo que nos permite - de entrada - pensar en las formas en que el texto y la imagen remiten a una experiencia que no termina de ser capturada. Dos de los rasgos del grabado me interesan en particular pensando en lo que se ve y lo que se da a ver: la forma cónica del cerro de Potosí, y el dibujo de un cerro pequeño que queda enmarcado en el perfil del cerro mayor.

Cieza no alude en su texto a la forma específica del cerro, el cual se describe, como recién leímos, evocando solo su altura, hermosura y buen asiento. Este perfil aparece, sin embargo, en otros textos de conocedores del entorno potosino que producidos pocas décadas después. Está presente en el texto de Luis Capoche, que data de 1585, cuyo original está perdido y que estaba acompañado de un "retrato o dibujo" de la Villa imperial y su Cerro Rico (Hanke, 1959, pp. 43-44). Minero y vecino de Potosí, la narración de Capoche se inicia con una poderosa evocación sensorial en la que el frío, el viento, y la oscuridad provocada por el polvo y la arena en suspensión (1585/1959, p. 75). Estos elementos son el contexto en que se describe lo que se ve y se vive, en contacto con el terreno:

Volviendo, pues, al cerro, en él no se cría hierba. Su color tira a rojo oscuro, limpio de peñas y riscos, abierto [cubierto] por la superficie con tierra y pedregal y desmontes con ley de plata. Lo restante es de peña. Está derecho y empinado, con subida agria, aunque se anda todo a caballo. Remátase en punta en forma redonda; tiene de boj y contorno una lengua por su falda. Está exento, suelto y dividido de la demás tierra,

\footnotetext{
6 Collado es, según el Thesoro de la lengua castellana de Sebastián de Covarrubias "tierra levantada, pero la que no llega a serlo tanto que la llamemos monte” (1611, p. 447), lo que se reitera en el Diccionario de autoridades, al definirlo como "La tierra que se levanta como cerro, y que por su poca altura no se llama monte ni sierra” (1729, p. 416).

Juan de Matienzo, quien fuera oidor de la Audiencia de Charcas, también describe el cerro como hermoso en su obra de 1567: "Potosi es un cerro muy hermoso; al derredor de el no hay otro ninguno. Descubriose por un yanacona de un Villarroel: año de 1547 (sic). Esta a un lado del cerro poblado un gran pueblo, tan grande como esta ciudad, habra dos años que el Virrey y Comisarios le hicieron villa" (1567/1967, p. 132).
} 
aunque por la parte del mediodía se le pegan unos collados y por la del poniente le nacen otros, de la hechura y facción que aquí va retratado $(*)^{7}$ (que está al natural, reduciendo su grandeza a esta pequeña demostración en su población e iglesias en los sitios que les pertenecen) (Capoche, 1585/1959, p. 76, énfasis propio).

Pocos años después, en su monumental Historia natural y moral de las Indias, el jesuita José de Acosta describe el cerro en semejantes términos, por lo que debió tener el escrito de Capoche a mano. De todos modos, Acosta conocía personalmente la ciudad. Entre las diferencias que distinguen los relatos de Capoche y Acosta destaca el uso de la expresión "pan de azúcar", modo instituido en la época para evocar una forma del relieve y un procedimiento de representación cartográfica del relieve mismo (Dainville, 1964, p. 168):

La color de este cerro tira a rojo oscuro; tiene una graciosísima vista, a modo de un pabellón igual, o un pan de azúcar, empinase y señorea todos los otros cerros que hay en su contorno; su subida es agra, aunque se anda toda a caballo; remátese en punta en forma redonda: tiene de boj y contorno una legua por su falda (Acosta, 1590, pp. 206-207, énfasis y traducción propios).

Derecho y empinado, con punta redondeada; con forma de pan de azúcar ${ }^{8}$, o como "punta de diamante", según se había consignado en una relación levantada por el presbítero Rodrigo de la Fuente Sanct Angel en 1572, a quien reconocemos como otro conocedor de la cuidad y su gente: "Dijo que bajando de lo más alto del cerro, vino un viento tan grande, que dio con él en tierra, cosa acaecida muchas veces en este cerro de Potosí ser en él grandes los vientos, por estar escombrado de todas partes y haberle criado naturaleza a hechura de una punta de diamante" (De la Fuente, 1572/1965, p. 359). Todos los autores citados buscaban particularizar el perfil del Cerro Rico, diferenciándolo del paisaje circundante.

$7 \quad$ El asterisco es del editor del volumen, quien informa en nota al pie que "[...] no consta el retrato al que alude el texto" (1959, p. 76).

8 Antonio de la Calancha, fraile agustino, describe el cerro en los mismos términos: "La forma del cerro es como un pan de açucar, i qual un gigáte se engríe i sobrepuja otros cerros que mira como a enanos, con ser Caricari i Tolosi bien altos, que le miran anbos lados, parecen pages que le miran al rostro, subese sin trabajo a mula despues que el comú tragin le á écho enos agrio" (1638, p. 743). En el libro recién aparecido de Andrea Doré se consigna igualmente una descripción del Cerro Rico que hace Garcilaso de la Vega en sus Comentarios Reales de los Incas, de la cual no tenía conocimiento, como un "pilón de azúcar" (Doré, 2020, 78). 
En estos textos se consignaba, además, que a los pies del Cerro Rico se encontraba un pequeño cerro, conocido como Guayna Potosí. En palabras de Capoche:

En este cerro, al pie de su falda, está incorporado un cerro pequeño que nace de él, que antiguamente tuvo algunas minas de metales sueltos que se hallan en bolsas y eran muy ricas, aunque pocas, y no iban fijos en vetas. Llámanlo Guayna Potosí, que quiere decir Potosí el Mozo, desde cuya falda, a la parte norte, comienza la población de esta villa la cual tiene de contorno ocho mil y seiscientas y cuenta y dos varas, que son una legua y seis cuartas (1585/1959, p. 76).

En este caso, la Historia de Acosta reproduce, casi palabra por palabra, la presentación del Guayna Potosí ${ }^{9}$, mientras el agustino Antonio de la Calancha agrega: "Huaynapotosi, que quiere decir Potosi el moço, o el ijo pequeño de Potosi” (1638, p. 743).

Todas estas descripciones salen de la pluma de personas que, como ya se ha dicho, habían estado en Potosí, ya sea como moradores permanentes o visitantes de paso. En todas estas, se enfatizan dimensiones visuales del objeto referenciado. Para el argumento que desarrollo acá, resulta muy clarificador un texto bastante posterior, obra de Bartolomé Arzáns de Orsúa y Vela ${ }^{10}$. Su Historia de la Villa Imperial de Potosí, escrita en las primeras décadas del siglo xviıI, en Potosí, presenta una descripción del cerro, en la que señala:

Y dejando aparte su interior hermosura que tanto deleita, aprovecha y abastece a los humanos (que se verá después), digo que la exterior es tan agradable a la vista que ninguno llega a verla sin que deje de causarle deleite y

$9 \quad$ Puede leerse en Acosta: "En este cerro, al pie de su falta, está otro cerro pequeño que nace de él, el cual antiguamente tuvo algunas minas de metales sueltos, que se hallaban como en bolsas y no en veta fija, y eran muy ricos, aunque pocos; llámanle Guayna Potosí, que quiere decir Potosí el mozo. De la falda de este pequeño cerro comienza la población de españoles o indio, que han venido a la riqueza y labor de Potosí. Tendrá la dicha población dos leguas de contorno; en ella es el mayor concurso y contratación que hay en el Perú” (1590, p. 207).

La alusión a la antigua explotación del oro en el 'Guayna Potosí' queda igualmente consignada en la relación de Rodrigo de la Fuente Sanct Angel: "Y así se bajaron sin conseguir lo questaba manifiesto y llegaron a lo que hoy se dice "Guaina Potosí", y le dijo el español Olmedo: 'en este lugar hay minas de plata, que no donde me llevaste, que no hay sino zupayes o demonios', que lo mesmo quiere decir" (1572/1965, pp. 360-361).

10 Como ya adelanté, en Vega (2019), propuse una lectura de Arzáns y su Cerro Rico. En ese texto me centré en las nociones de imaginación geográfica y en los conceptos ubicarsey orientales del geógrafo Paul Claval para pensar en la relación entre escritura corográfica y relato imperial. Remito a ese texto para una revisión más detallada de la obra de Arzáns. 
admiración, obligándoles a alabar al Criador, la especialidad de su bella forma. La cual (como queda dicho en el capítulo I de la Primera parte esta Historia) es como la de un pan de azúcar o pabellón muy extendido, por la falda. Su altura de poco más de una legua que la tiene desde el pie del cerro pequeño que llaman los indios Huayna Potosí, que se interpreta Potosi el mozo (el cual nace del cuerpo grande y se dilata un gran espacio, pero mirado del pueblo parece estar pegado el uno al otro, y siendo de la misma forma del cerro grande quedan entrambos con muy buena perfección (1965, I, p. 63, énfasis propio).

Tal como puede leerse en esta cita de Arzáns, el Cerro Rico y el Guayna Potosí son formas de relieve diferentes, cuya extensión recubre un espacio dilatado; sin embargo, vistos desde el entorno de la ciudad, parecen superponerse, donde el pequeño replica la forma del mayor. Esta vista fue la que Cieza de León recogió en su grabado, lo que describieron quienes se abocaron a dar cuenta del entorno de la gran mina de plata y lo que siguieron relevando quienes dibujaron o pintaron este entorno, no como una mera copia de la imagen de Cieza, sino como un renovado ejercicio de observación.

Ahora bien, esta conclusión parcial requiere de todos modos una precisión, porque la forma de ver adoptada ha de pensarse no solo desde las dimensiones materiales que derivan de la localización de quien mira, sino - tal como adelantábamos más arriba- de una práctica social. Dos cuestiones derivan de este aserto. La primera es explicitar que la localización es la del asentamiento colonial, su planta urbana y de la vista que ofrecen la ciudad y el cerro, desde su plaza mayor.

De manera complementaria, reconocer el acto de observar como una práctica social permite imaginar que las descripciones previas — que pudieron estar presentes en el habla corriente y que recogen los textos citados - y las imágenes que circularon —en distintos espacios, con accesos diferenciados, pero que debieron verse en la misma cuidadtambién alimentaron y orientaron los nuevos procesos de observación. Pensando específicamente en relación con el trabajo del artista pintor, Gombrich señala: "Lo familiar seguirá siendo siempre el más probable punto de partida para la expresión de lo no familiar [...]. La pintura es una actividad y por consiguiente el artista tenderá a ver lo que pinta más que a pintar lo que ve" (Gombrich, 1996, pp. 72-73). Más recientemente, Kusukawa ha elaborado sobre esta relación entre imagen y visión, sugiriendo que "las imágenes son una de las formas mediante las cuales 
Figura 2. Vista de Potosí y Cerro Rico

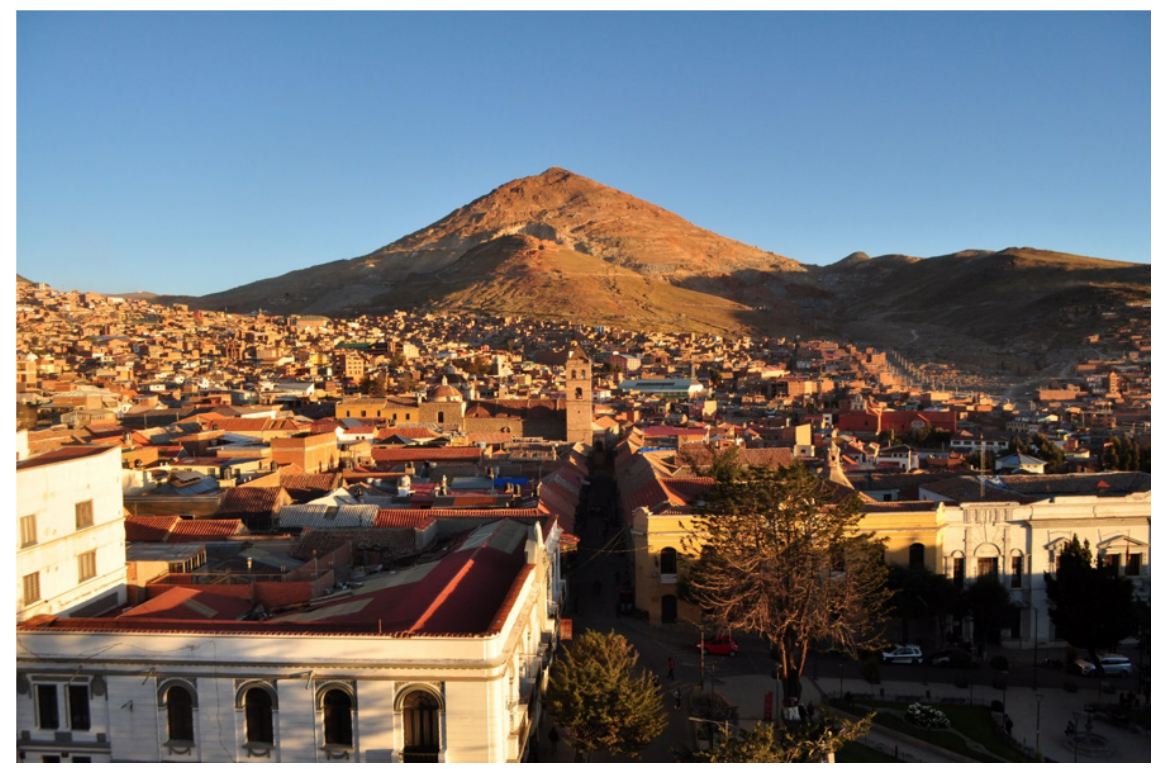

Fuente: Fabian Kronenberger, licencia CC BY-ND 2.0

el proceso del 'mirar' puede hacerse concreto y visible. A través de una imagen, un objeto puede ser visualizado y comprendido” (2012, p. 20, traducción propia). Podemos pensar entonces que la existencia efectiva de un repertorio de imágenes textuales y visuales interactuaba con las prácticas efectivas de observación y que su exitosa circulación reforzaba, a cada paso, la relación entre lo visto y lo representado.

De comienzos del siglo XviI data la siguiente imagen que quisiera comentar. Se trata de una vista del cerro y las faenas mineras, una pieza anónima de un tratado de 17 páginas, realizado en torno a 1605 por algún funcionario colonial, buen conocedor de la mina y sus labores ${ }^{11}$.

Quisiera llamar la atención acerca de los elementos de continuidad que pueden reconocerse entre esta vista urbana y el grabado de Cieza y, en particular, el doble perfil del Cerro Rico y del Cerro Chico; así como su peso visual. Adicionalmente, hay un interés por representar la explotación de la plata, expresado en la actividad de la mano de obra y los hatos de llamas, las

11 El documento contiene igualmente una planta urbana, cuya factura tiene rasgos formales diferentes a la vista que analizaremos. No obstante, comparte la orientación del espacio con esta, dado que coloca el sur en la parte superior del plano cartográfico. El cerro no se representa, quedando en el "afuera" de la imagen, la que termina con una línea que designa la "halda del cerro" [sic]" ("La villa ymperial de Potossi", ca. 1605). 
Figura 3. Sin título. Potosi y su Cerro Rico

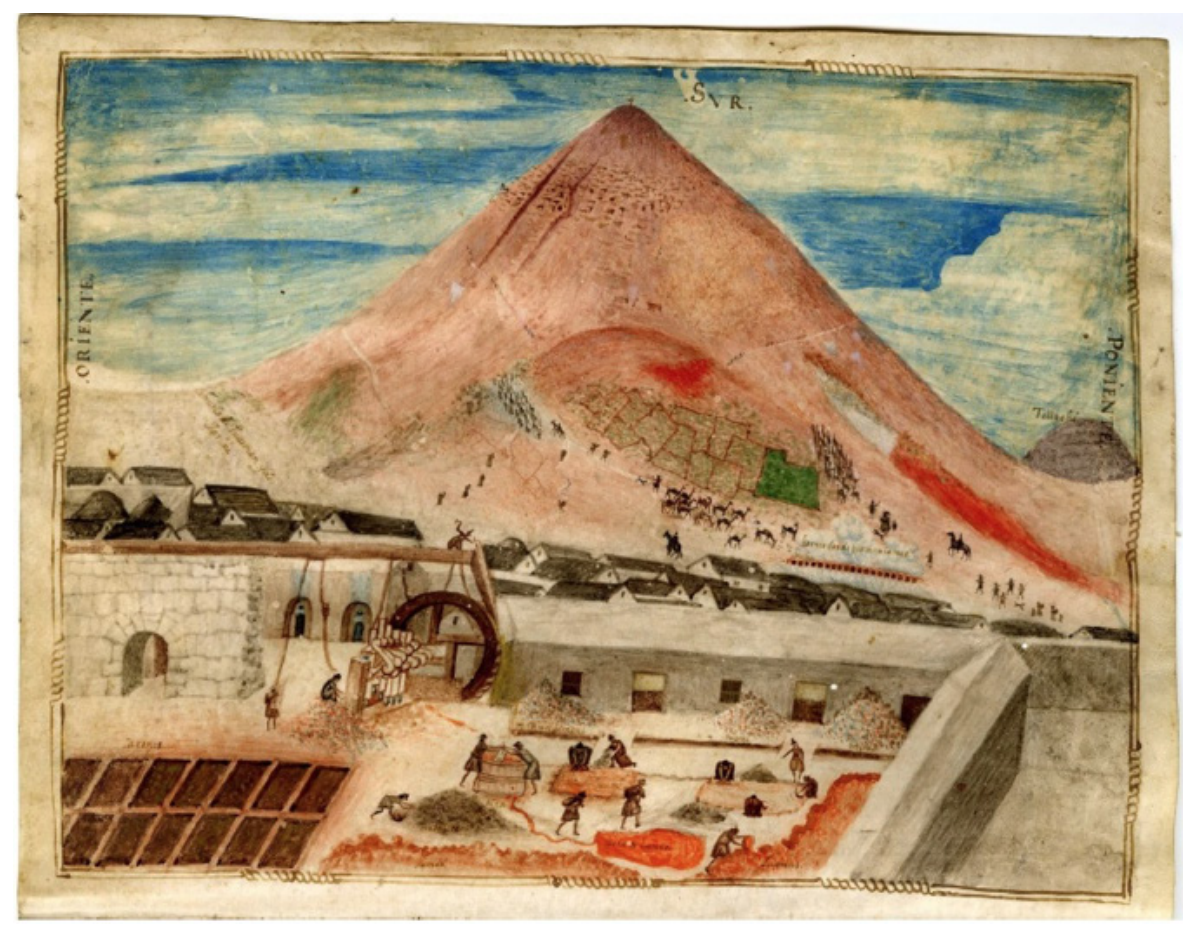

Nota. Dibujo de tinta sobre papel, Hispanic Society of America, ms K3.

vetas y los colores del mineral, así como en la infraestructura asociada a la explotación del yacimiento. A un costado, se dibuja además un cerro pequeño y más oscuro, el cual también puede observarse desde el entramado urbano de la ciudad colonial (figura 2). Con una toponimia cambiante, en este caso "Tollochi”, encontraremos este cerro en otras iconografías posteriores ${ }^{12}$.

Adicionalmente, las inscripciones "sur", "poniente" y "oriente" nos informan que esta vista, al igual que la de Cieza ya comentada, se construye con el sur en la parte superior del plano representado.

Veamos ahora una planta urbana que ocupa un lugar problemático en nuestro corpus. Se trata de un dibujo realizado muy probablemente durante la segunda mitad del siglo xix, perteneciente al Archivo y

12 Véase, más adelante, el cerro Huacache, que se consigna en la planta urbana anónima presentada como figura 4, y el cerro Tawacoñuño, que se registra en la pintura titulada Entrada del virrey arzobispo Morcillo en Potosí, obra de Melchor Pérez de Holguín.

Arzáns distingue estos cerros en su descripción del entorno potosino. El Tollosi [sic], ubicado en cercanías del Caricari (al este del Cerro Rico); "el cerro de Huaccáchec, que se ve a su espalda" (1965, I, p. 66). Por su parte, Tavacoñuño [sic] sería "un cerro de la forma de una teta que está más arriba (que es lo mismo que en nuestro castellano que pecho de mujer moza)” (1965, I, 157). 
Figura 4. Potosí. Vista de Potosí (dibujo del siglo XVII) [sic]

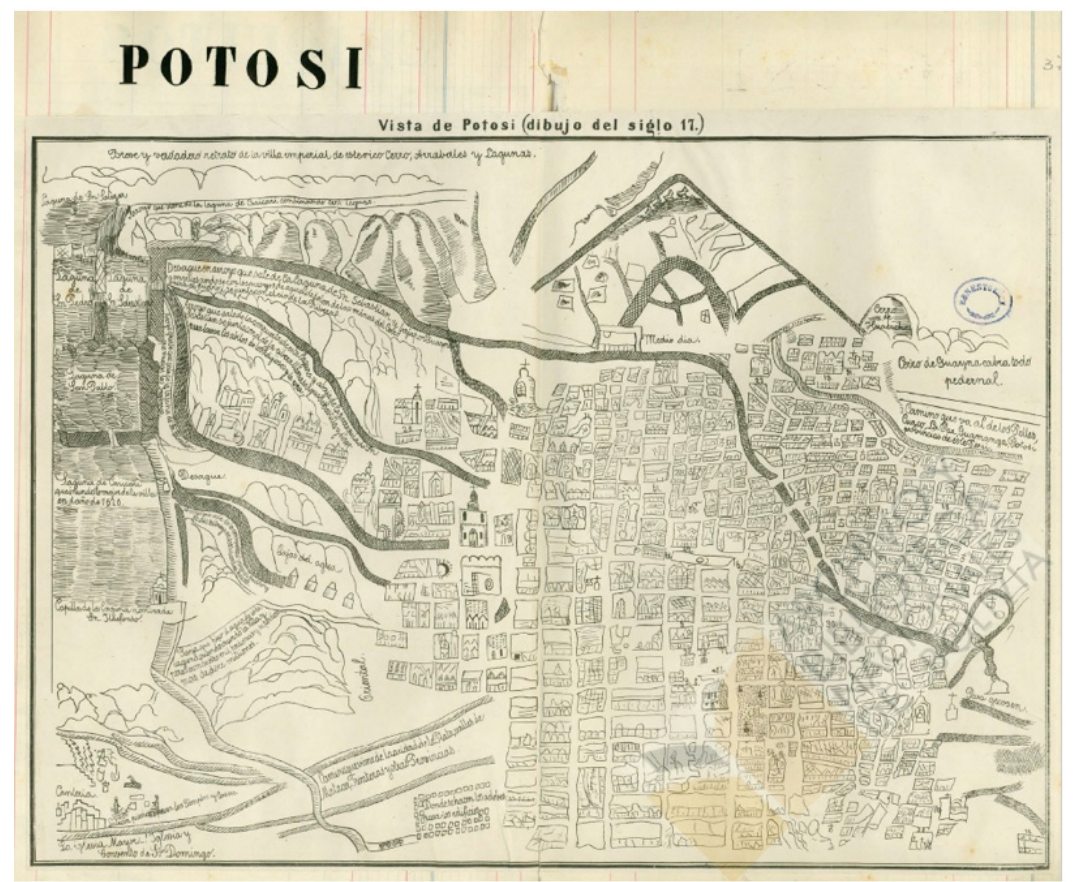

Nota. Fondo Rück, 249-III-38, Archivo y Biblioteca Nacionales de Bolivia.

Biblioteca Nacional de Bolivia, Fondo Rück, y que figura en el catálogo impreso de dicho fondo como Vista de Potosí (dibujo del siglo XVII). Breve y verdadero retrato de la Villa Imperial de este Cerro Rico, arrabales y lagunas.

Se impone acá un breve desvío. El Fondo Rück se constituyó al comprar la Biblioteca Nacional de Bolivia la colección con empaste decimonónico de impresos y manuscritos de los siglos XVI al xIx del ingeniero y bibliófilo Ernesto Rück, quien había sido el primer director del Archivo General de la Nación de dicho país. Antes de la venta, Rück había mandado imprimir en Lima el catálogo de los documentos que componían los volúmenes de su colección, y que consigna la referencia a la lámina que comentamos (Mendoza, 1961/2010, pp. 37-38). De modo que se trata de una pieza que quedó registrada, desde el siglo xıx, como si fuera obra del periodo colonial, pese a tratarse, evidentemente, de una copia posterior.

Por las características del trazado urbano y el tipo de leyendas que el mapa contiene, podemos suponer que se trata de una copia posterior, quizás decimonónica, de una planta urbana de dicha ciudad, ya sea 
de mediados del siglo XVII o de comienzos del siglo XVIII ${ }^{[13]}$. También resulta evidente que el mapa formaba parte de algún escrito mayor, por los números inscritos en la planta que hacen referencia a una cartela inexistente de leyendas.

Tal como se presenta a nosotros esta copia, el retrato de la villa imperial conserva algunos rasgos reconocibles: su orientación, el doble perfil cónico del relieve potosino con sus vetas, la regularidad del trazado urbano y los caminos que comunican a Potosí con el vasto espacio surandino $^{14}$. Al igual que la vista urbana recién presentada, encarna el modo de ver de la ciudad ya instituido, incluyendo el cerro pequeño y oscuro que acompaña al doble perfil cónico de la mina, acá identificado como Cerro de Huacache.

En la línea de lo que hemos venido argumentando, estas imágenes son formas de ver que compartieron diferentes sectores hispanos o criollos que habitan o conocen Potosí, tales como sacerdotes, mineros, funcionarios del aparato burocrático. Lo mismo puede decirse de otro sector social, el de los pintores. En efecto, hay varias pinturas del siglo XVIII que pueden referirse, porque nos hablan de la pertinencia y la amplitud social de este fenómeno. Destaco tres de ellas. La primera es la conocida Virgen del cerro de Potosí, un óleo sobre tela anónimo, de factura altoperuana, la cual se encuentra hoy en el Museo Casa Nacional de Moneda de Potosí. Esta pintura está vinculada con una serie de obras que desarrollan la asociación simbólica entre cerro y virgen (Gisbert, 1980, pp. 17-19). No me detendré en el problema de la interpretación general de esta — su vinculación con huacas prehispánicas, el debate entre su lectura como obra "sincrética" de lo andino y cristiano, o su relación con la emblemática y la condición de jeroglifo de la virgen-cerro-, pues no me parece fundamental para el asunto que acá se discute ${ }^{15}$. Lo relevante es que, en el marco de una representación que dialoga con funciones, productores o destinatarios de un discurso religioso, se recurre al doble perfil cónico presente en la iconografía potosina para dar cuenta de ese espacio y hacerlo plenamente reconocible.

La segunda pintura que me interesa está firmada en 1716. La Entrada del virrey arzobispo Morcillo en Potosí, actualmente en la colección

13 La planta refiere a la inundación de la Villa por efecto del rebalse de la laguna de Caricari, que ocurrió en 1626.

14 La planta urbana de ca. 1605, referida en nota al pie número 16, también muestra los caminos que comunican a Potosí con el espacio del centro sur andino.

15 Véanse, entre otros, Gisbert (1980, 2010); Eichmann (2007-2008); Cruz (2009). 
del Museo de América de Madrid, es obra de Melchor Pérez de Holguín, el más destacado y prolífico pintor radicado en Potosí a comienzos de este siglo (Gisbert \& De Mesa, 2012, pp. 159-170). Su factura responde a una tipología bien difundida tanto en Europa como en América: el registro de grandes celebraciones político-religiosas. Siguiendo las reglas del género, se busca particularizar el escenario del festejo, recogiendo las características de las construcciones arquitectónicas y la geografía. En el campo principal de la pintura destacan la procesión y la ciudad engalanada. Dos recuadros secundarios permiten retratar otros momentos de la ceremoniosa entrada y recepción de la figura virreinal. Entre las tres escenas, se compone una vista del entorno natural, una suerte de anfiteatro semicircular que contiene y sirve de fondo a los hechos retratados. En el recuadro superior izquierdo, nos encontramos con el Cerro Rico y el Cerro Chico, acompañado a la derecha del pequeño y oscuro cerro, acá bautizado Tawacoñuño; mientras en la escena central, a la mano derecha del observador, destacan otros cerros con su toponimia. Lo que se privilegia acá es la ciudad como expresión del orden social y político. Sin embargo, esto no opaca la voluntad manifiesta del pintor por consignar el relieve circundante y hacer de este una parte de la fiesta.

Este mismo gesto, el de la descripción orográfica, se expresa monumentalmente en otra obra que como la propia cartela señala, "se pintó en la misma villa" (figura 5). Se trata de una pintura de Gaspar Miguel de Berríos, destacado pintor potosino, discípulo de Melchor Pérez de Holguíny que lleva por título Descripcion del zerro rico e ymperial villa de Potosí (Gisbert \& De Mesa, 2012, pp. 172-174). Está fechada por su autor en 1758.

En esta pintura, pueden observarse ciertas particularidades, las que comparte, entre otras, con la planta urbana del Fondo Rück que ya vimos, tales como su amplia panorámica del entorno del yacimiento y la villa imperial, y su interés por representar la extraordinaria ingeniería hidráulica al servicio de la producción de plata en la forma de una red de lagunas, embalses y canales.

En este marco, se adoptan numerosos rasgos que hemos venido observando en las vistas y plantas precedentes: su construcción con el sur arriba; el doble perfil cónico característico del relieve potosino, acompañado de ese pequeño cerro oscuro, acá sin nombre; la intensa actividad que se despliega en las laderas del cerro; la línea de ingenios para el tratamiento del mineral; los caminos que unen a la ciudad con la región circundante, y la extensa trama urbana regular, en la que destacan las edificaciones religiosas y las instituciones del gobierno de la ciudad. 
Figura 5. Miguel Gaspar de Berrio, Descripción del zerro rico e ymperial villa de Potosí, 1758

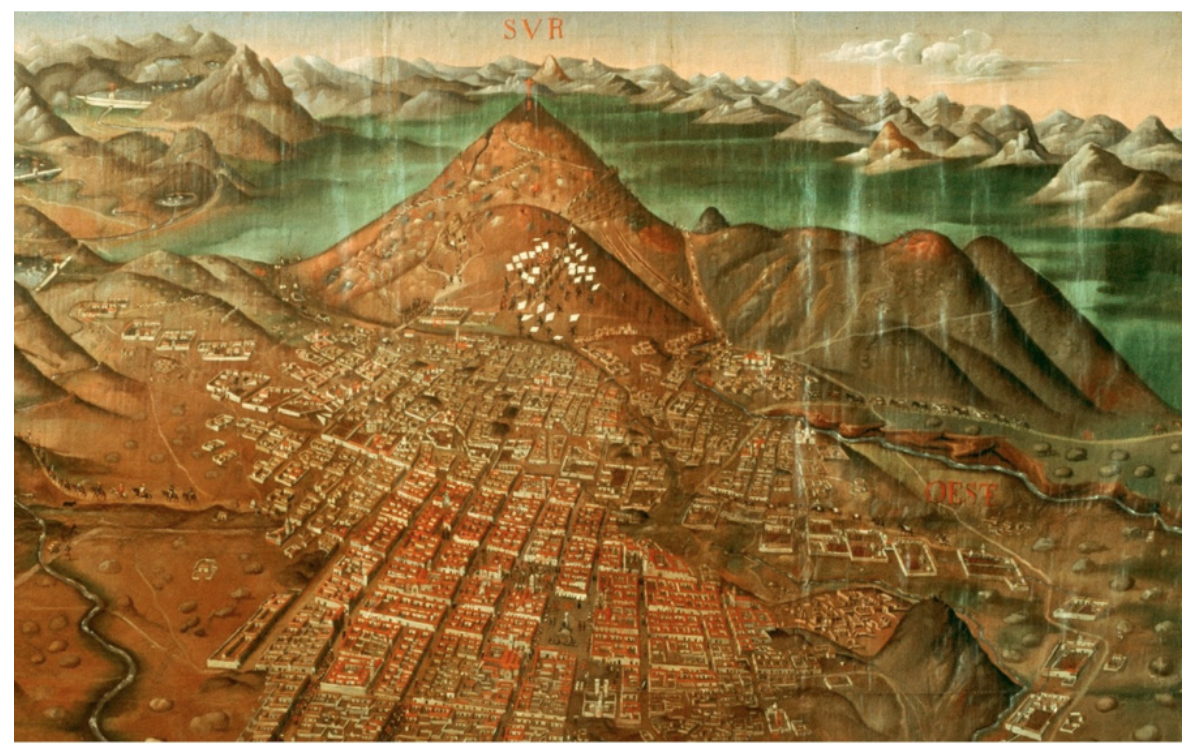

Nota. Óleo sobre lienzo, Museo Colonial Charcas.

Como cierre de esta secuencia, quisiera recordar los dibujos incluido en la Historia de la villa imperial de Potosí de Bartolomé Arzáns de Orsúa y Vela, vecino de la ciudad rica, obra que quedó inconclusa debido a la muerte de su autor en 1736, y que ya evocábamos antes. En este caso, la imagen aparece en dos formatos: integrada al escudo que habría obsequiado Carlos $\mathrm{V}$ a la Villarrica en el frontispicio de la obra ${ }^{16}$, y a modo de viñeta con la que se rematan algunos de los capítulos interiores de la primera parte ${ }^{17}$. Como tal, oscila entre el escudo y el emblema al articular un sentido de lo real, una carga moral, y un repertorio específico de alegorías y analogías a partir de la combinación de imagen y texto (Michel, 1981). Nuevamente, nos encontramos con otra tipología de imagen, una que, fiel a las reglas de su especificidad tipológica, recurre de todos modos a las formas de ver expresadas en el doble perfil cónico del Cerro Rico de Potosí.

16 Fuertes López $(2010,2015)$ discute la cuestión de los escudos de armas que la Villa Imperial recibió efectivamente durante el periodo colonial.

17 Una única viñera en el Manuscrito de Madrid, siete en el Manuscrito de Brown (Mendoza 1965, pp. 461-462). 


\section{APUNTES PARA UNA CONGLUSIÓN}

El corpus de imágenes que hemos revisado narra historias de éxito de la sociedad local potosina. Este ha sido nuestro punto de partida, en diálogo con trabajos que — con distintos enfoques y alcances- han revisado la iconografía asociada a la Villa rica de Potosí. Lo que aparece como una cierta secuencia de imágenes es, lo reitero ahora, una red de objetos situados, obra de artífices que dialogaban con su tiempo y las expectativas de sus públicos destinatarios. No hay acá un recorrido ascendente que culmine con un cierto tipo de imagen. Lo que quisiera sugerir apunta en otras direcciones.

En primer lugar, me parece importante valorar la temprana articulación entre un lugar y un modo de ver. No solo un topónimo - Potosí-, sino una experiencia y una cultura visual, expresadas en un encuadre, una orientación, unas formas familiares que identificaban al Cerro Rico y a la ciudad que gozaba de su prestigio en el concierto del mundo. Al realizar una lectura integrada de estas imágenes - en este caso vistas, pinturas conmemorativas y devocionales, emblemas y plantas urbanas - puede observarse con mayor precisión los énfasis de las prácticas de registro y la cultura visual imperante en un contexto dado. En ese sentido, podemos reconocer el énfasis paisajístico-estético o topográfico de alguna de estas obras, sus ecos simbólicos o su vocación naturalista, sin por esto olvidar que todas son modulaciones del vínculo que establecen los sectores hispanos y criollos de Potosí con su ciudad y su entorno, anudados en torno a una determinada forma de ver.

En este caso, destaca la reiteración del doble perfil cónico, que se ubica en la parte superior del plano de la representación, quedando de este modo la vista orientada hacia el Sur, tal y como se ve la ciudad desde adentro, desde su planta urbana colonial. Los énfasis de las distintas vistas urbanas podían suscitar en el observador memorias o relatos que - mientras hacían reconocible el lugar y lo vinculaban con un espacio más amplio, imperial o universal - resultaban a su vez tremendamente familiares.

En consecuencia, podemos reevaluar la repetición de figuras que hasta ahora habían sido leídas como formas convencionales y reconocer que dicha repetición se alimenta, en el ámbito local, de la institución de un punto de vista. La existencia efectiva de imágenes textuales o visuales seguramente alimentó la experiencia sensorial de dicho entorno, de modo 
que su exitosa circulación reforzaba, a cada paso, la relación entre lo visto y lo representado. Es desde esa perspectiva que podemos reevaluar el grabado de Cieza de 1553 y lo que siguieron dibujando quienes se abocaron a dar cuenta de la Villa Rica, no como una mera copia de la imagen de Cieza, sino como un renovado ejercicio de observación situada y de colectivo reconocimiento de la especificidad de Potosí y su Cerro Rico.

\section{REFERENCIAS}

Acosta, J. de (1590). Historia natural y moral de las Indias. Casa de Juan de León.

Alpers, S. (1983). The Art of Describing: Dutch Art in the Seventeenth Century. University of Chicago Press.

Arzáns de Orsúa y Vela, B. (1965). Historia de la villa imperial de Potosi. (L. Hanke \& G. Mendoza, Eds., Vols. 1-3). Brown University Press.

Assadourian, C. S. (1983). El sistema de la economía colonial. El mercado interior. Regiones y espacio económico. Editorial Nueva Imagen.

Bajtin, M. (1998). Estética de la creación verbal. Siglo XXI Editores.

Bal, M. (2002). Travelling concepts in the Humanities. University of Toronto Press.

Barragán, R. (2019). Potosí global. Viajando con sus primeras imágenes. Plural editores.

Baxandall, M. (1972). Painting and Experience in Fifteenth Century Italy. Oxford University Press.

Berger, J. (2010). Modos de ver. Gustavo Gili.

Besse, J.M. (2000). Voir la terre. Six essais sur le paysage et la géographie. Actes Sud.

Besse, J. M (2009). Le goût du monde. Exercices de paysage. Actes Sud.

Buisseret, D. (2003). The Mapmaker's Quest: Depicting New Worlds in Renaissance Europe. Oxford University Press.

Calancha, fray A. de la. (1638). Coronica moraliza del Orden de San Augustin en el Peru con sucesos ejemplares en esta Monarquía (Vol. I). Pedro Lacavalleria, Calle de la Librería.

Capoche, L. (1585/1959). Relación general de la Villa Imperial de Potosí. Un capítulo inédito en la historia del nuevo mundo. En Biblioteca de autores españoles (Vol. CXXII, pp. 69-223). Ediciones Atlas.

Cieza de León, P. de. (1553). Primera parte dela Chronica del Perú. Casa de Martín de Montesdoca.

Cieza de León, P. de. (1553/1996). Crónica del Perú. Primera parte. Pontificia Universidad Católica del Perú, Academia Nacional de la Historia.

Cook, N. D. (2010). La catástrofe demográfica andina. Perú 1520-1620. Pontificia Universidad Católica del Perú.

Covarrubias, S. (1611). Thesoro de la lengua castellana o española. En L. Sánchez (Ed.), Nuevo Tesoro Lexicográfico. Real Academia Española. http://ntlle.rae.es/ ntlle/SrvltGUILoginNtlle. 
Cruz, P. (2009). Huacas olvidadas y cerros santos. Apuntes metodológicos sobre la cartografía sagrada en los Andes del sur de Bolivia. Estudios Atacameños. Arqueología y Antropología Surandinas, 38, 55-74.

Dainville, F (1964). Le langage des géographes. Termes, signes, couleurs des cartes anciennes (1500-1800). Editions A. et J. Picard.

De la Fuente, R. (1572/1965). Relación del Cerro de Potosí y su descubrimiento. En M. Jiménez de la Espada (Ed.), Relaciones Geográficas de Indias. Perú (Vol. I, pp. 357-361). Ediciones Atlas.

De Matienzo, J. (1567/1967). Gobierno del Perú con todas las cosas pertenecientes a él y a su historia (G. Lohmann Villena, Ed.). IFEA.

Diccionario de Autoridades. (1726-1770). En Nuevo Tesoro Lexicográfico. Real Academia Española. http://ntlle.rae.es/ntlle/SrvltGUILoginNtlle.

Doré, A. (2020). Cartografia da promessa. Potosi e o Brasil em um continente chamado Peruana. Editora Intermeios.

Eichmann, A. (2007-2008). La Virgen-cerro de Potosí: ¿Arte mestizo o expresión emblemática? Revista de Historia Americana y Argentina, Tercera época, 42-43, 37-60.

Fossa, L. (s. f.). Proyecto Glosas Croniquenses. https://glosascroniquenses.github.io/ proyecto/.

Fuertes López, J. A. (2010). Creación de la Villa Imperial de Potosí. La capitulación de 1561. Biblioteca del Bicentenario.

Fuertes López, J. A. (2015). La Historia detrás del Escudo de Armas de la Villa Imperial de Potosí. El Cerro Rico de Potosí. Símbolo heráldico. Gobierno Autónomo Municipal de Potosí/Secretaría de Desarrollo Humano y Cultura.

Gisbert, T. (1980). Iconografía y mitos indígenas en el arte. Gisbert y Cia. S.A. Libreros y Editores.

Gisbert, T. (2010). El cerro de Potosí y el Dios Pachacámac. Chungará, Revista de Antropología Chilena, 42(1), 169-180.

Gisbert, T. \& J. de Mesa (2012). Historia del arte en Bolivia. Periodo virreinal. Artes gráficas Sagitario SRL.

Gombrich, E. H. (1996). Arte e ilusión. Estudio sobre la psicología de la representación pictórica. Debate.

Hanke, L. (1959). Luis Capoche y la Historia de Potosí. En Biblioteca de Autores Españoles (Vol. CXXII, pp. 40-68). Ediciones Atlas.

Kagan, R. (2000). Urban Images of the Hispanic World 1493-1793. Yale University Press.

Kopytoff, I. (1991). La biografía cultural de las cosas: la mercantilización como proceso. En A. Appadurai (Ed.), La vida social de las cosas: perspectiva cultural de las mercancías (pp. 89-122). Consejo Nacional para la Cultura y las Artes.

Kusukawa, S. (2012). Picturing the book of nature: Image, text and argument in sixteenthcentury human anatomy and medical botany. University of Chicago Press.

Medinaceli, X. (2011). Potosí y La Plata: la experiencia de la ciudad andina (siglos XVI y XVII). En A. Eichmann y M. Inch C. (Eds.), La construcción de lo urbano en Potosi y La Plata. Siglos XVI y XVII (pp. 1-145). Ministerio de Cultura 
de España, Fundación Cultural del Banco Central de Bolivia y Archivo y Biblioteca Nacionales de Bolivia.

Mendoza, G. (1965). Análisis de los manuscritos de la Historia de Potosí utilizados para esta edición. En B. Arzáns de Orsúa \& L. Hanke (Eds.), Historia de la villa imperial de Potosí (Vol. 3, pp. 461-46). Brown University Press.

Mendoza, G. (1961/2010). Homenaje a Ernst Otto Rück patrocinado por el Archivo y Biblioteca Nacionales de Bolivia. Revista de la Biblioteca y Archivo Histórico de la Asamblea Legislativa Plurinacional, 4(9), 35-44.

Michel, A. (1981). Rhétorique et philosophie de l'emblème, Allégorie, Réalisme, Fable. En M. T. Jones-Davies (Ed.), Emblèmes et devises au temps de la Renaissance (pp. 23-31). Université de Paris-Sorbonne, Centre de Recherches sur la Renaissance.

Mignolo, W. (1982). Cartas, crónicas y relaciones del descubrimiento y la conquista. En L. I. Madrigal (Ed.), Historia de la literatura hispanoamericana (Vol. I, pp. 57-102). Ediciones Cátedra.

Mitchell, W.J.T. (1986). Iconology. Image, text, ideology. The University of Chicago Press.

La villa ymperial de Potossi. (ca. 1605). K3. Hispanic Society of America.

Pease, F. (1995). Las crónicas y los Andes. Fondo de Cultura Económica.

Penhos, M. (2005). Ver, conocer, dominar. Imágenes de Sudamérica a fines del siglo XVIII. Siglo XXI Editores.

Silvestri, G. (2012). El lugar común. Una historia de las figuras de paisaje en el Río de la Plata. Edhasa.

Tandeter, E. (2002). Coacción y mercado: la minería de la plata en el Potosí colonial, 1692-1826. Siglo XXI Editores.

Vega, A. (2015). Espacio imperial, espacio local. Discursos superpuestos en mapas y pinturas de la Villa Imperial de Potosí, siglos xvi-Xviır. En M. Nieto y S. Díaz (Eds.), Dibujar y pintar el mundo: arte, cartografía y política (pp. 106-109). Universidad de los Andes/ Razón cartográfica/ Red de historias de las geografías y cartografías de Colombia.

Vega, A. (2019). El orbe desde Potosí: ubicarse y orientarse en la Historia de la Villa Imperial de Potosí de Bartolomé Arzáns de Orsúa y Vela. En S. Tieffemberg (Ed.), Pensar América desde sus colonias. Textos e imágenes de América Colonial (pp. 249-274). Editorial Biblos.

Wagner, K. (1982). Martín de Montesdoca y su prensa. Contribución al estudio de la imprenta y de la bibliografía sevillanas del siglo XVI. Universidad de Sevilla. 